\title{
Ageing and Long-Term Care: Key Challenges in Long-Term Care Coverage for Public and Private Systems
}

\author{
Henri de Castries \\ AXA Group, 25 avenue Matignon, Paris 75008, France.
}

Ageing populations in developed countries are being driven by strong social and structural demographic movements leading to a significant growth in the over 65 population. In the light of this, long-term care costs will be a major threat to individual assets and public finances over the next 40 years. Existing public schemes covering long-term care exhibit some significant issues, driven by pay-as-you-go designs combined with weak risk definitions. These difficulties will accelerate the need for new financing sources to cover the risk and call for early preparation by both public and private sectors. A new and advantageous public-private partnership has to be invented to meet the ambition of a sustainable and universal coverage. Against this background, key challenges facing the insurers include increasing public awareness of long-term care costs and challenges, risk monitoring and designing innovative and robust solutions for both wealth accumulation and protection products.

The Geneva Papers (2009) 34, 24-34. doi:10.1057/gpp.2008.41

Keywords: long-term care; ageing; public and private schemes; universal coverage; protection products

\section{Introduction}

The traditional pay-as-you-go long-term care social insurance scheme is no longer sustainable facing the challenge of an ageing population. Major public schemes covering long-term care exhibit some significant funding issues and moreover provide benefits that are insufficient to cover the costs, particularly in the case of a severe loss of autonomy. An international study conducted by AXA shows that people are concerned about the cost of long-term care and see themselves as underinsured. An international comparison of both public schemes and private long-term care insurance markets highlights the importance of a robust definition of the circumstances in which the benefits are payable. Simple protection products, both efficient and flexible by nature, are gradually becoming more and more popular around the world. In the coming years the key challenges faced by insurers are forging partnerships with the public sector in order to educate the population about the financial risk of long-term care and designing a scheme and products that will best meet the needs of the public.

\section{Long-term care needs are driven by strong structural demographic movements in developed countries}

The ageing of populations, driven by strong social and demographic trends, represents a major challenge and an inevitable change in all developed countries. General 


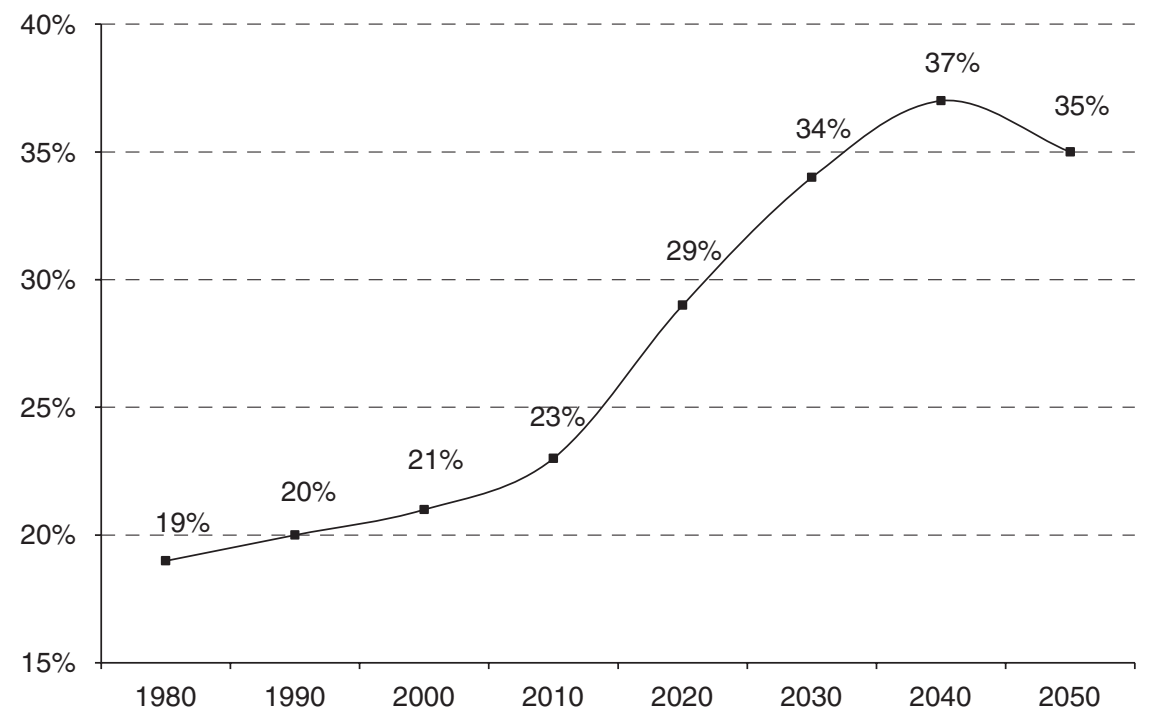

Figure 1. Percentage of 65 years and older compared to 15 to 64 years old (OECD). Source: OECD.

improvement of health as well as enhanced medical techniques and increased focus on preventive care have led to a significant rise in life expectancy. These structural factors have seen their effects amplified by limited immigration, especially in Western Europe, and by the "baby boom generation effect".

Altogether, this has led to a significant growth in the over 65 population. ${ }^{1}$ As shown in Figure 1, the average percentage of persons aged 65 years and older in the Organisation for Economic Co-operation and Development (OECD) countries compared to those aged from 15 to 64 years will have nearly doubled between 1980 and 2040, reaching an alarming peak of 37 percent.

Such evolution in the demographic structure of the population will necessarily entail a growing strain on public budgets. Correspondingly, it will accelerate the need for new financing sources to cover long-term care and retirement expenditures. For instance, in France we expect that the population eligible for public schemes will grow at a rate of 2 percent per annum over the next 30 years (source: AXA internal calculations).

A more recent study by EUROSTAT $(2008)^{2}$ has concluded that there will be a significant increase of the most elderly part of the European population. According to this study, the proportion of total population aged 65 years or over is

${ }^{1}$ Lafortune and Balestat (2007).

2 Giannakouris (2008) with a EUROSTAT study based on the EUROPOP2008 "convergence scenario", and on the population on 1 January 2008. The assumptions have been developed in a conceptual framework where the socio-economic and cultural differences between member states of the European Union would fade away in the long run (convergence year 2150). Migration is assumed to converge to zero net migration. 
EU: Average public expenditure on health and long-term care, in euros

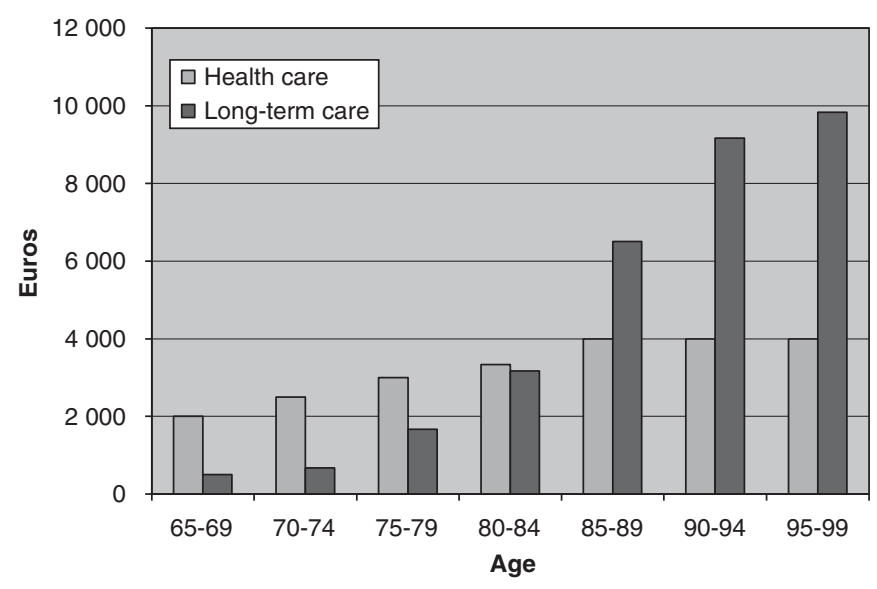

Figure 2. Average public expenditure in Europe by age.

Source: Adapted from data in Economic Policy Committee (2001).

projected to increase from 17.1 per cent in 2008 to 30.0 per cent in 2060 in the European Union (EU). Similarly, the number of people aged 80 years or over is projected to almost triple from 4.5 per cent in 2008 to 12 per cent in 2060, with some countries with rates approaching 15 per cent (Italy, Spain). Another interesting result within the EU is that while there are four persons of working age (15-64 years old) for every person aged 65 years or over in 2008, the ratio is expected to be 2 to 1 in 2060 .

This inevitable ageing of the population of the OECD countries accelerates the need for new financing sources to cover retirement and long-term care. Pay-as-you-go retirement schemes are already having to cope with funding issues. Advance preparation over many years for both public and private schemes is required.

Long-term care costs are a major threat to individual assets and public finances over the next 40 years. Compared to the average public expenditure on health, the average public expenditure on long-term care increases dramatically with age. This illustrates the key issue governments are facing in nearly all OECD countries with the ageing of the population (Figure 2).

Along with these public cost figures, long-term care costs can substantially affect individual assets. Cost for severe loss of autonomy in France can be estimated around $€ 35,000$ per annum per patient. Long-term care costs may be even significantly higher for people suffering from Alzheimer's disease.

In its 2008 national education campaign to better inform consumers about their risks of needing long-term care, the America's Health Insurance Plans (AHIP) found that 1 year in a nursing home costs an average of $\$ 75,000$. That same year, a study on long-term care costs ${ }^{3}$ across the United States showed that it can cost even more than

\footnotetext{
${ }^{3}$ Prudential, 2008.
} 


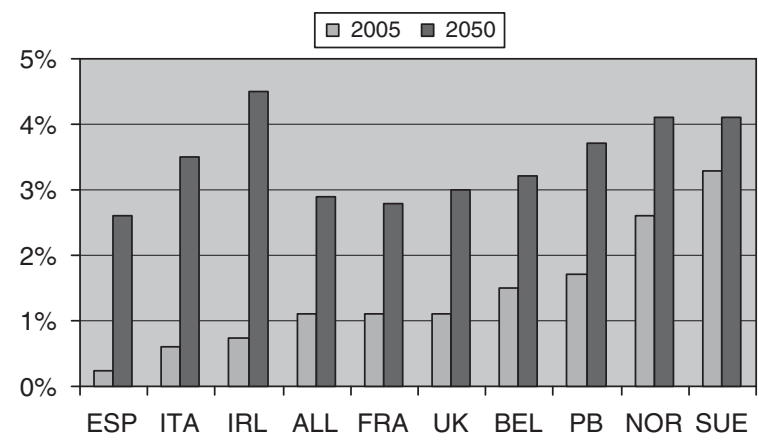

Figure 3. 2050 projection of long-term care public expenditures as percent of GDP. Source: OECD, Projecting Long-term Care Expenditures, 2006.

that. According to the study, average costs for long-term care services increased over the past 2 years and are expected to continue to rise. The largest increase was among assisted living facilities, increasing about 13 per cent from $2006 .^{4}$

Figure 3 depicts that long-term care expenditures are expected to grow significantly over the next 40 years in all EU countries. These projections take into account both demographic impacts and non-demographic impacts such as wage inflation and the decrease of informal care.

These long-term care expenditures currently range from 0.2 to 3 per cent of GDP in European countries with an average of 1 per cent for countries such as France, Germany and the United Kingdom. ${ }^{5}$ These expenditures are expected to represent 3-4 per cent in 2050 for most European countries.

Significant individual wealth is needed to cope with the financial requirements of long-term care.

In Table 1, we have estimated the level of assets needed for a person at age 25, 50 and 65 to get a sufficient return to cover their needs in case of dependency.

Two major conclusions can be drawn from these simulations: that individual assets necessary to cover long-term care financial needs are indeed significant, and that wealth accumulation should start at early ages to avoid excessive yearly contributions.

\section{People appear worried about long-term care and feel underinsured}

What is the awareness of people regarding long-term care risk? Are they thinking about getting protected against it? An international study recently conducted by AXA

\footnotetext{
${ }^{4}$ The average cost to live in an assisted living community in 2008 is about $\$ 39,000$ per year. Nursing home rates increased more than 7 per cent, which means that the average annual cost of a private nursing home room in 2008 is $\$ 79,000$. A semi-private room costs on average $\$ 70,810$ a year. These costs vary across states.

${ }^{5}$ OECD Economics Department (2006).
} 
The Geneva Papers on Risk and Insurance - Issues and Practice

28

Table 1 Estimation of level of assets needed to cover LTC costs

\begin{tabular}{|c|c|c|c|c|c|c|c|c|c|}
\hline \multirow[t]{2}{*}{ Age } & \multicolumn{3}{|c|}{25 years } & \multicolumn{3}{|c|}{50 years } & \multicolumn{3}{|c|}{65 years } \\
\hline & $\begin{array}{c}\text { Scenario } \\
1\end{array}$ & $\begin{array}{c}\text { Scenario } \\
2\end{array}$ & $\begin{array}{l}\text { Diff. } \\
(\%)\end{array}$ & $\begin{array}{c}\text { Scenario } \\
1\end{array}$ & $\begin{array}{c}\text { Scenario } \\
2\end{array}$ & $\begin{array}{l}\text { Diff. } \\
(\%)\end{array}$ & $\begin{array}{c}\text { Scenario } \\
1\end{array}$ & $\begin{array}{c}\text { Scenario } \\
2\end{array}$ & $\begin{array}{l}\text { Diff. } \\
(\%)\end{array}$ \\
\hline $\begin{array}{l}\text { Initial wealth } \\
\text { required (in euros) }\end{array}$ & 18,190 & 6,406 & -65 & 53,376 & 30,207 & -43 & 101,825 & 76,601 & -25 \\
\hline $\begin{array}{l}\text { Equivalent annual } \\
\text { contribution until } \\
\text { retirement ( } 60 \text { years } \\
\text { old) (in euros) }\end{array}$ & 82 & 36 & -56 & 536 & 328 & -39 & NA & NA & NA \\
\hline
\end{tabular}

Scenario 1: 100 per cent of wealth invested in European Government bonds.

Scenario 2: 50 per cent of wealth allocated to equity instruments.

Source: internal AXA calculations, based on the following assumptions: dependent at age 80 during 5 years, need for $€ 1,500$ per month indexed at 4 per cent p.a., risk-free rate at 4.4 per cent, equity risk premium at 3.5 per cent, no mutualisation effects.

Table 2 An approach of LTC risk awareness

\begin{tabular}{lllr}
\hline Top five life risks & & Consequences of life risks (\%) \\
\hline Serious illness & $\mathbf{1}$ & Death & 73 \\
Serious car accident & 2 & Financial hardship & 65 \\
Serious financial problems & 3 & Temporary disability & 62 \\
Domestic or sport accident & 4 & Permanent loss of autonomy & $\mathbf{5 9}$ \\
Unemployment & 5 & Downsizing your standard of living & 57 \\
& & None & 6 \\
\hline
\end{tabular}

Source: AXA international survey (2007).

in a range of developed countries ${ }^{6}$ shows that people appear worried about a serious illness and about the permanent loss of autonomy and its consequences (shown in bold in Table 2). In other words, they are concerned about long-term care.

Nevertheless, long-term care product penetration is lower than other protection products. Even though we include disability products with long-term care, the ownership is lower (54 per cent) compared to Health insurance (69 per cent) or life insurance (64 per cent).

Correspondingly, people in nearly all countries see themselves as underinsured. There is a clear need for protection products and wealth accumulation products (Figure 4).

This study also showed that while people appear to be worried about long-term care, fatalistic attitudes lead them to insufficient preparation. This survey sheds some light on what the consumers perceive as the most important benefits of protection products. The first is the protection of family or relatives, followed by peace of mind and protection of financial assets (shown in bold in Table 3).

${ }^{6}$ AXA report (2007) was an international survey conducted in March 2007 by AXA in 11 countries: Australia, Belgium, France, Germany, Hong Kong, Italy, Japan, Spain, Switzerland, the U.K. and the U.S.A. 


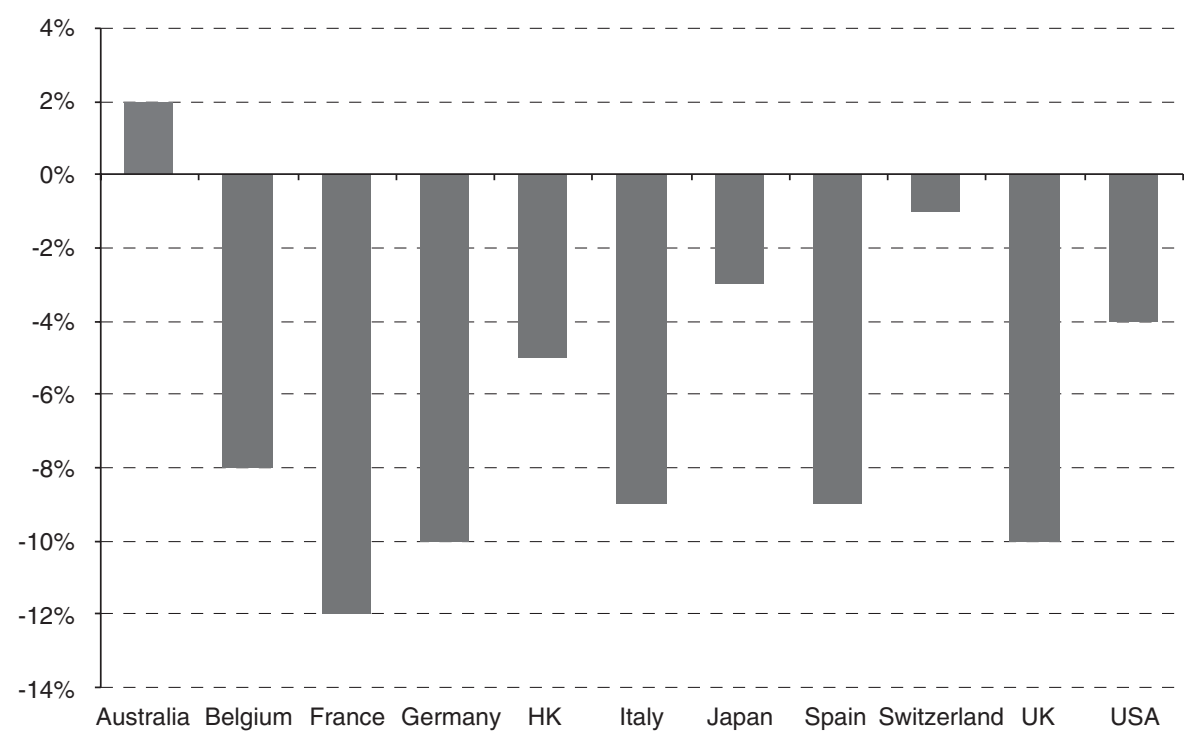

Figure 4. Perceived gap between estimated needs and covers.

Source: AXA international survey (2007).

Table 3 A sense of attitudes and perceptions

\begin{tabular}{lrlr}
\hline Attitude towards life risks (\%) & \multicolumn{2}{c}{ Perception of insurance products (\%) } \\
\hline Risk avoiders & 31 & Protect your family/relatives & $\mathbf{6 5}$ \\
Risk aware but no preparation & $\mathbf{2 7}$ & Give you peace of mind & $\mathbf{6 0}$ \\
Fatalistic & $\mathbf{2 5}$ & Protect your financial assets & $\mathbf{4 5}$ \\
Risk taker & 8 & A necessary evil & 43 \\
Risk denier & 7 & A waste of money & 15 \\
None & 2 & None & 3 \\
\hline
\end{tabular}

Source: AXA international survey (2007).

The long-term care risk awareness exists in the majority of OECD countries, who have a common need for protection products due to the fact that the burden of longterm care cannot rely only on national solidarity. So far the answer provided by public schemes remains insufficient to cover the costs related to long-term care.

\section{Major public schemes covering long-term care exhibit significant issues, especially regarding the definition of dependency and financing}

We can distinguish three major traditional categories of long-term care coverage by public schemes. ${ }^{7}$ In the "Bismarkian" system - applied most notably in Austria, Germany, Luxembourg and Japan - long-term care is a pillar of social insurance (the

\footnotetext{
${ }^{7}$ Assous (2001).
} 
fifth pillar with compulsory social insurance). The "Beveridgian" system is applied in two main groups of countries. The first, including Denmark, Sweden and Finland, is based on a social democracy ideology and has a long-term care system with generous benefits. The second group consists of more liberal countries and less generous long-term care funding and includes United Kingdom and Ireland. A third system consists of social care and is implemented in Italy, Spain (where there is an ongoing reform) and Portugal.

More and more long-term care systems do not fit exactly into one of these categories. Hybrid models, some of which combine public and private coverage, are emerging in countries such as Belgium, France (ongoing reform), Spain, Singapore (Eldershield) and the U.S.A. (Medicaid, Medicare).

Three recent situations of the increasing difficulties of financing long-term care can be illustrated. In Belgium, definition issues have led to a doubling of levies dedicated to long-term care 3 years after the launch of the plan. In Germany, the Government announced in March 2008 that levies dedicated to the plan would be raised by 15 per cent which is expected to ensure financial stability over the next 5-7 years. In France, there is an ongoing reform to meet the challenge of long-term care; this is the "Fifth risk" plan that the French government is expected to implement in 2009.

Pay-as-you-go schemes combined with the coverage of the first stages of the loss of autonomy are driving these difficulties. In comparison, the Singaporean plan, which relies on insurers' expertise, appears much more sustainable in the long run.

Figure 5 gives a typical example of financing issues faced by public bodies for longterm care.

The traditional pay-as-you-go scheme is no longer sustainable. Our projections highlight that, based on a central scenario, public benefits will experience an annual growth of 3.8 per cent over the next 30 years, which is significantly above expected GDP growth. This negative spread will create an additional burden for the French

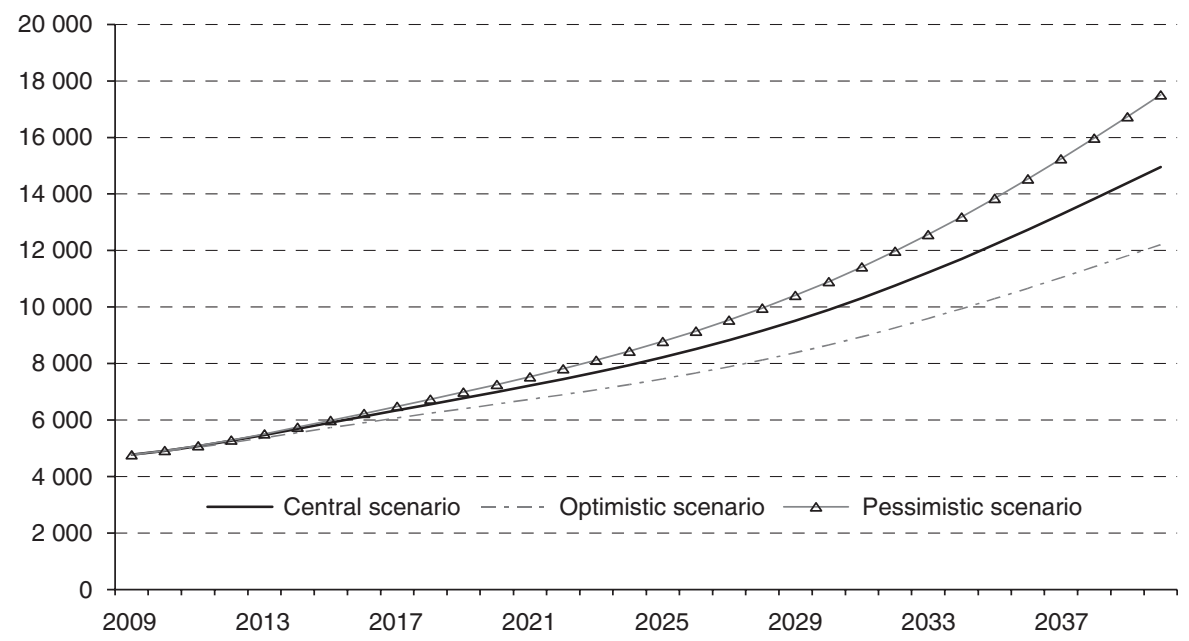

Figure 5. Probable evolution of public spending in France (APA) if no structural reform occurs (€ millions). Source: internal AXA calculations, based on projection of the French population, best estimate projection of underlying risks (three scenarios) and a 1.8 per cent increase in benefits per annum (average growth of benefits). 
Table 4 Eldershield plan: observed opt-out rate level

\begin{tabular}{lc}
\hline Year & Opt-out rate $(\%)$ \\
\hline 2002 (launch) & 38 \\
2002 (Q4) & 30 \\
2003 & 25 \\
2004 & 21 \\
2005 & 18 \\
2006 & 14 \\
\hline
\end{tabular}

budget. Without action, expenditure growth could be close to 4 per cent per annum over the next few years, reflecting the ageing of the generation born after World War II. Public expenditure will double over the next 20 years.

The Eldershield plan in Singapore is based on an advantageous partnership between public bodies and private players. This scheme is based on a private insurance scheme with automatic enrolment for persons between 40 and 69 years old. It is possible to refuse the private coverage (opt-out) during the first 3 months. If one opts out, neither subsidies from public bodies nor preferred underwriting conditions would be provided in the future. Products, pricing and claims management are the responsibility of private insurers, selected by the government following a request for proposal (RFP). Products are standardised with a lifetime guarantee of a temporary annuity in case of long-term care ( $\$ 400$ for 6 years, above current long-term care length experience).

The Eldershield plan appears highly beneficial as it allows a clear and effective separation of functions: distribution of wealth is managed by public bodies, whereas pricing and risk management are fully managed by private insurers and are transparent to the public. Communication and prevention responsibilities are shared between government and insurers. The plan was rolled out in 2002 with an automatic enrolment of all people between 40 and 69 years old living in Singapore.

The Singaporean government has financed a share of the premium for those aged from 55 to 69 years old to smooth age discrimination. People over 70 years old or those already disabled are receiving public benefits depending on their income. A large awareness campaign of risks has been carried out in order to promote the plan and the products.

The decreasing opt-out rate level (see Table 4) reflects the popularity of the plan.

The eligibility criteria of the Eldershield scheme are a severe loss of autonomy. The robust definition of the loss of autonomy remains a key feature to manage this risk.

\section{The importance of the long-term care definition}

Many definitions of long-term care exist across the world and vary widely among countries. Most public coverage systems use some specific grids covering several levels of loss of autonomy, often with weak definitions. ${ }^{8}$

\footnotetext{
${ }^{8}$ Taleyson (2008).
} 
Capability of performing "Activities of Daily Living" (ADL) is the most common criteria applied by insurance companies. The definition is often based on the inability to perform these ADLs without assistance. There are some differences across countries in terms of the number of ADLs taken into account and the definition of each.

Loss of autonomy generates a financial need to pay for formal and informal care, services and a variety of health care costs incurred to assist dependent people in performing daily living activities.

Funding issues of public long-term care schemes in many OECD countries are closely related to a weak definition of the dependency risk. The eligibility criteria based on the definition of long-term care is the cornerstone of the insurance product. For cash benefits products, the loss of autonomy covered should be irreversible.

This definition needs to be simple, precise, easy-to-understand by the insured, relevant and compatible with consumer need. An effective benefit trigger should be objective, reproducible, measurable, quantifiable and expressed in a way that can be consistently interpreted by claims assessors, underwriters and actuaries. The eligibility criteria should be related to both the loss of functional capacity and severe cognitive impairment. Defined in this way, the severe loss of autonomy is easier to specify and monitor.

\section{Simple protection products are gaining momentum across the world}

The two main long-term care insurance markets, both having more than 20 years of experience, are France and the U.S. However, they are each based on different models. With 3 million policyholders, the French market is the most developed private longterm care insurance market in Europe. The products are based on cash benefit products, which derive their success from their simple features. These simple protection products have experienced strong growth through 2006. Another characteristic of these products is their technical robustness with respect to eligibility criteria as well as risk modelling, pricing, risk management, etc.

In the U.S., the long-term care insurance market, with 6 million policyholders, is twice as big as the French one. However, it is smaller as a percentage of the population and is a declining market, experiencing negative growth for individual products and the exit of major players. Long-term care products developed in the U.S. are based on reimbursement products. These reimbursement products are often complex and raise significant technical issues regarding pricing and risk monitoring.

The "cash benefit model" covering the severe loss of autonomy has already been exported to various European countries (such as Italy and Spain) and to Asian countries, most notably South Korea, Japan and Singapore. The simple protection products offered under this model are both efficient and flexible. They are efficient because they are easyto-understand and to sell while also being technically robust and they are flexible because they provide a fixed amount of cash that can be converted into services to fit the wishes and the needs of each individual. This flexibility is a key requirement for customers.

\section{What are the key challenges ahead for insurers?}

Existing public schemes with pay-as-you-go designs are not able to cope with funding issues related to ageing and a rise in medical and non-medical services costs. Therefore, 
the need for private insurance will grow along with the need to be protected against the loss of autonomy through sustainable funding. Long-term care is a question of both protection and wealth accumulation.

One of the first challenges facing insurers is to succeed with public bodies in increasing public awareness of long-term care risk and its financial consequences. Another challenge is to provide robust products to the market. The increasing nursing and health care costs for disabled people are very difficult to reflect adequately in the pricing of reimbursement products, as it is impossible to guarantee long-term care costs over the next decades. Simple protection products with cash benefits guaranteeing an annuity in case of dependency and convertible into services remain much more robust and flexible in meeting long-term care needs. The dependent policyholders are free to use their annuities to pay for formal or informal care, and are free to stay at home or enter a nursing home. These products appear successful and more easily manageable if they are based on a robust definition of the loss of autonomy. Private insurers are also able to design innovative solutions for wealth accumulation solutions such as variable annuities.

Long-term care risk remains an evolving and complex risk to monitor and manage. Some insurers have developed enough expertise and credible experience to build up some simple products that are easier to manage. A risk management approach must be embedded in the product life cycle.

To cope with the demographic challenges and with the solvency of the population in case of a severe loss of autonomy, a universal coverage should be developed. We could imagine the key features of a cooperative public/private partnership in this area. The building of a new scheme could rely on the upholding or reinforcement of current public benefit plans for people who are not able to get immediate private coverage, such as either already disabled people or people above a certain age (e.g. 70 years old). A pillar of this universal insurance could be an automatic enrolment feature with the freedom to opt-out of the scheme, based on simple protection products and corresponding to agreed industry quality standards.

In order to give broad access to this scheme and strong incentives to issue protection policies, some public subsidies could help with the transition generation and the low-income population to fund their premiums, thus reducing age discrimination and making the cover affordable to everyone. A simplified underwriting would be set up to reduce discrimination related to the health status. Again, in order to foster individual responsibility, some awareness communication campaigns would be required.

This type of architecture could yield significant benefits. A universal insurance would mean reaching the highest coverage rate and leveraging the largest mutualisation effect. This would be in line with economics and with the principle of social justice. Public subsidies would reinforce the attractiveness and affordability for all customers. It would also provide the nation with a robust funding of the risk, consistent with its long-term nature and leading to the creation of individual allocated "savings". Last but not least, such a scheme would also have very positive impacts on the overall economy. Not only would it reduce pressure on public budgets, but it would also provide an incremental financing source for the economy and ensure individual solvency in confronting this risk. 


\section{Conclusion}

Funding long-term care represents a major and growing challenge in all developed countries. What is at stake is not simply to "patch up" public benefits to cope with this additional burden on public budgets, but to invent a new model that would allow for both a universal and a sustainable coverage of the population. Given the threat that long-term care represents to individual assets, early preparation is needed. Both public and private sectors should join forces to raise public awareness of the long-term care risk, particularly among young generations. Education is the first step to make individuals responsible for being protected against this risk. Private long-term care insurance markets are meant to play an increasingly important role in the future to complete insufficient public benefits. To meet this challenge, insurers will have to develop innovative and robust solutions both in the field of wealth management and regarding protection products. Some beneficial public-private partnerships can be set up to catalyse the development of the long-term care markets with simple, affordable and flexible protection products to cover this complex risk. This could pave the way for other major reforms in the social and economic fields.

\section{References}

Assous, L. (2001) 'Long-term health and social care for the elderly: An international perspective', The Geneva Papers on Risk and Insurance - Issues and Practice 26(4): 667-683.

AXA (2007) AXA Protection Report.

EC-Economic Policy Committee (2001) Budgetary challenges posed by ageing populations: The impact on public spending on pensions, health and long-term care for the elderly and possible indicators of the long-term sustainability of public finances, EPC/ECFIN/655/01-EN final, October.

Giannakouris, K (2008) 'Ageing characterises the demographic perspectives of the European societies', EUROSTAT Statistics in Focus, Population and Social Conditions 72: 1-12.

Lafortune, G., Balestat, G. and the Disability Study Expert Group Members (2007) Trends in severe disability among elderly people: Assessing the evidence in 12 OECD countries and the future implications, OECD Health Working papers 26, Paris.

OECD Economics Department (2006) Projecting OECD health and long-term care expenditures: What are the main drivers? Working papers 477 , OECD, Paris.

Prudential (2008) 'Long-term care cost study', Research report (August 2008), 4-9.

Taleyson, L (2008) 'L'enjeu de la définition de la dépendance: Une comparaison internationale', Risques 72 : $28-35$.

\section{About the Author}

Henri de Castries studied business at HEC (Ecole des "Hautes études commerciales") in Paris and obtained a law degree in 1976 before entering the French National School of Administration (ENA). He began his career with the French Finance Ministry Inspection Office in 1980 and then joined the French Treasury Department in 1984. He joined AXA in 1989 where he held various positions in the company in France and in the U.S. He has been Chairman of the AXA Management Board since May 2000. 